\title{
Empiema por Fusobacterium necrophorum
}

\author{
Empiema caused by Fusobacterium necrophorum
}

\author{
ML. Valle Feijo0 ${ }^{1}$, M. Rodriguez Arias ${ }^{1}$, A. Cobas Paz², J. de la Fuente Aguado'. \\ ${ }^{1}$ Servicio Medicina Interna. ${ }^{2}$ Servicio Neumología. Hospital Povisa. Vigo
}

\begin{abstract}
Resumen
La infección sistémica por Fusobacterium necrophorum se caracteriza por la tríada clásica de trombosis de la vena yugular interna, bacteriemia y focos metastásicos y se conoce como Síndrome de Lemierre (SL), sepsis post-angina o necrobacilosis. El compromiso pulmonar precipitado por la embolización séptica es extremadamente común en el SL, sin embargo el F. necrohorum raramente se asila en empiemas sin SL concurrente, por lo que hemos estimado oportuno comunicar un nuevo caso clínico.

Palabras clave: Fusobacterium necrophorum, empiema
\end{abstract}

\section{Introducción}

El Fusobacterium necrophorum es un bacilo gramnegativo, anaerobio estricto, que forman parte de la flora habitual de orofaringe, aparato digestivo y tracto genital femenino. Aunque puede provocar sepsis sin complicaciones trombóticas, bacteriemias, infecciones locales y en el puerperio, destaca por la infección invasora denominada Síndrome de Lemièrre (SL), caracterizada por la tríada clásica de trombosis de la vena yugular interna, bacteriemia y focos metastásicos. El compromiso pulmonar precipitado por la embolización séptica es extremadamente común en el SL, no obstante el F. necrohorum raramente se aisla en empiemas sin SL concurrente, por lo que hemos estimado oportuno comunicar un nuevo caso.

\section{Caso clínico}

Varón de 35 años, fumador de 10 cigarrillos/día y previamente sano. Acude al servicio de urgencias por dolor en base de hemitórax izquierdo de 15 días de evolución, que ponía en relación con caída accidental, acompañado de tos con expectoración purulenta y disnea de moderados esfuerzos en los últimos 4-5 días. No refería odinofagia ni había sido sometido a manipulaciones dentarias previamente. Negaba sudoración profusa, sensación distérmica, tos, síndrome constitucional o contactos recientes con pacientes tuberculosos. Se encontraba hemodinámicamente estable (TA 130/80 mmHg), taquicárdico (FC $100 \mathrm{lpm})$ y febril $\left(\mathrm{T}^{\mathrm{a}} 38,3^{\circ} \mathrm{C}\right)$. En cavidad oral destacaba la ausencia de varias piezas dentales y focos de periodontitis. No se palparon adenopatías cervicales ni se apreció ingurgitación yugular. No se auscultaron soplos cardíacos y la auscultación pulmonar mostró hallazgos semiológicos de derrame pleural en hemitoráx izquierdo. Analítica: leucocitosis (Leucocitos: 18.230) y trombocitosis (Plaquetas: 601.000), elevación de reactantes de fase aguda (VSG: 95, PCR: 22.8), con ionograma, función renal y hepática normales. La radiografía de tórax mostró ocupación de Lll y língula compatible con derrame pleural izquierdo y el TAC torácico reveló derrame pleural izquierdo loculado de importante cuantía con marcado realce de las hojas pleurales, así como adenopatías reactivas (Figura 1). Se le realizó toracocentesis diagnóstica, cumpliendo el líquido pleural criterios de empiema pleural, por lo que se decidió colocar un tubo de tórax para drenaje del mismo e iniciar tratamiento antibiótico correspondencia: Ivalle@povisa.es

Como citar este artículo: Valle Feijoo ML, Rodríguez Arias M, Cobas Paz A, de la Fuente Aguado J.

Empiema por fusobacterium necrophorum. Galicia Clin 2014; 75 (3): 131-132

Recibido: 15/'01/2014; Aceptado: 21/04/2014

\begin{abstract}
Systemic infection by Fusobacerium necrophorum is characterized by the classic triad of thrombosis of the jugular internal vein, bacteriemia and metastatic spread and it is known as Lemiere syndrome (LS), post-amigdalitis sepsis or necrobacillosis. Pulmonary impairement due to septic embolism is very common in LS, but Fusobacterium necrophorum is hardly ever found in empyemas without LS. We report a new case.

Key Words: Fusobacterium necrophorum, empyema
\end{abstract}

Figura 1. TAC torácico: derrame pleural loculado, realce de hojas pleurales y adenopatías reactivas

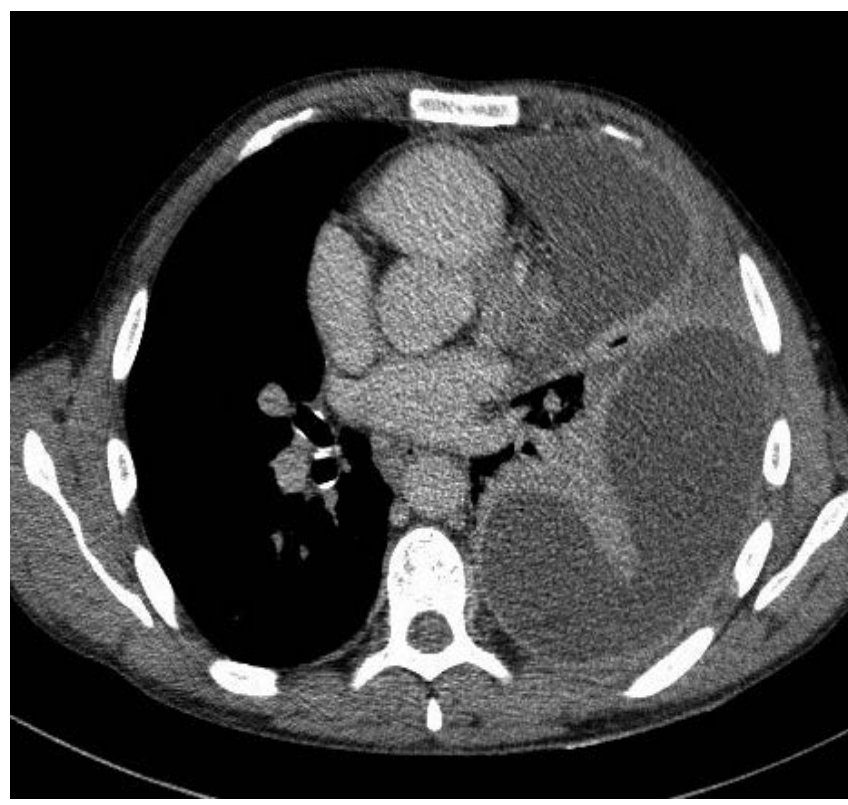

empírico con ceftriaxona y clindamicina. En el cultivo del líquido pleural se aisló F. necrophorum sensible a amoxicilina-clavulánico, cefoxitina, clindamicina, imipemem, metronidazol y penicilina y, tanto la tinción de auramina como el cultivo en medio Löwenstein del líquido fueron negativos. La ortopantografía reveló múltiples focos sépticos intraorales, por lo que fue planteada la realización de exodoncias. La evolución clínica fue tórpida, con necesidad de decorticación pleuropulmonar izquierda, complicada en el postoperatorio inmediato con hemotórax post-operatorio.

\section{Discusión}

El F. necrophorum, inicialmente denominado Bacillus funduliformis, es un bacilo gramnegativo pleomórfico, anaerobio estricto, no productor de esporas, que forma parte de la flora de orofaringe, tracto gastrointestinal y génitourinario y, en 
condiciones normales, no invade las mucosas intactas ${ }^{1}$. Conocido en veterinaria desde finales del siglo XIX por provocar necrobacilosis² , este término en la actualidad también se utiliza para definir la sepsis por F. necrophorum en humanos. La presentación clásica y más dramática de la enfermedad es el Síndrome de Lemièrre (SL) o sepsis post-angina que se caracteriza por la tríada de tromboflebitis séptica de la vena yugular interna, bacteriemia y abscesos metastásicos ${ }^{3}$. En la descripción clásica, el foco infeccioso es de origen faríngeo y precede 1-3 semanas al cuadro clínico (asociado en ocasiones a afectación amigdalina o periamigdalina). Otros focos descritos son infecciones odontógenas, sinusitis, mastoiditis o mononucleosis infecciosa1. En la "era pre-antibiótica" era una patología relativamente común y comportaba una elevada mortalidad $(90 \%)^{3,4}$. A partir de los años 40, con la llegada de la penicilina, se verificó una disminución progresiva de los casos, por lo que en publicaciones de los años 1980-1990 la denominaban "la enfermedad olvidada". No obstante, en las últimas dos décadas varios trabajos muestran un resurgimiento de la infección a escala mundial ${ }^{4}$, hecho que también se reportado en España ${ }^{5,6}$. Este aumento de incidencia está relacionado con políticas antibióticas que potencian un uso restringido de antibióticos en el tratamiento de las infecciones faríngeas ${ }^{2,7}$, la detección de cepas de fusobacterium productoras de betalactamasas $(22 \%)^{2}$ y la resistencia a macrólidos del F. necrophorum ${ }^{2,7}$. Otra posibilidad radica en los avances producidos en las técnicas de cultivo para bacterias anaerobias que se asocia con una mayor tasa de detección ${ }^{8}$. En la actualidad la mortalidad oscila entre 4-18\% dependiendo de las series ${ }^{4}$.

El compromiso pulmonar precipitado por la embolización séptica es extremadamente común (émbolos pulmonares, abscesos pulmonares, derrame paraneumónico o empiema) y ocurre en un 80-100\% de los casos, seguido de artritis séptica (13-27\%) y afectación de piel y tejidos blandos (0-16\%) función hepática es anormal hasta en un 49\% de los casos, con ictericia en un alto porcentaje de ellos, abscesos hepáticos múltiples y esplénicos ${ }^{8}$. Otras manifestaciones más raras son neurológicas (abscesos cerebrales, trombosis del seno cavernoso o sigmoide por diseminación retrógrada), endocarditis, renales (insuficiencia renal aguda, abscesos renales y glomerulonefritis) y hematológicas (trombocitopenia y CID) ${ }^{8}$.

A pesar que el compromiso pleuropulmonar es casi constante, el empiema por F. necrophorum en ausencia de SL es excepcional ${ }^{7}$. En una serie de casos, Hagelskjaer et al. hallaron F. necrophorum en un $4 \%$ de los empiemas ${ }^{9,10}$. En nuestro caso, el paciente presentaba múltiples focos sépticos en la cavidad oral, que podrían haber propiciado el desarrollo de bacteriemia por F. necrophorum y la neumonía con empiema pleural asociado en el contexto de traumatismo torácico. Tanto el inicio precoz del tratamiento antibiótico como el drenaje del mismo podrían haber abortado otras manifestaciones de la infección.

Otra especie del género fusobacterium, el F. nucleatum, forma parte de la flora orofaríngea y juega un papel crucial en la enfermedad periodontal. A semejanza del F. necrophorum, la diseminación de la infección puede alcanzar cerebro, hígado, articulaciones y válvulas cardíacas ${ }^{11}$, no obstante, el F. nucleatum es uno de los anaerobios que con más frecuencia se aisla en los empiemas pleurales. El F. necrophorum afecta más a jóvenes y adultos sanos, sin embargo la población afectada por el F. nucleatum es de mayor edad y presenta comorbilidades, como insuficiencia renal en hemodiálisis 0 neoplasias ${ }^{11}$.

Las infecciones por F. necrophorum requieren un tratamiento antibiótlico prolongado, así como drenaje de las colecciones². Se recomienda emplear un antibiótico betactámico resistente a betalactamasas. Aproximadamente un 95\% de las cepas son sensibles a penicilina, clindamicina, metronidazol, amoxicilinaclavulánico e imipenem y suelen ser resistentes a macrólidos y cefalosporinas de tercera generación ${ }^{6}$.

A pesar de que la infección por $F$. necrophorum en humanos es rara, es necesario estar atento a los posibles escenarios clínicos de la infección para identificarla y tratar sus complicaciones.

\section{Bibliografía}

1. Hagelskjaer Kristensen L, Prag J. Human necrobacillosis with emphasis on Lemierre's syndrome. Clin Infect Dis 2000; 31: 524-532.

2. Riordan T. Human Infection with Fusobacterium necrophorum (necrobacillosis) with focus on Lemierre Syndrome. Clin Microbiol Rev 2007;20: 622-659.

3. Lemierre A. On certain septicemias due to anaerobic organisms. Lancet. 1936; 1: 701-703.

4. Brazier JS. Human infections with Fusobacterium necrophorum. Anaerobe 2006;12: 165-172.

5. Gargallo E, Nuevo JA, Cano JC, Castuera Al, Andueza JA, Fernández M. Síndrome de Lemierre: distintas presentaciones clínicas de una «enfermedad olvidada». Enferm Infecc Microbiol Clin. 2010;28: 701-705.

6. García-Sánchez JE, García-Sánchez E, Martín-Del-Rey A, García-Merino E Las bacterias anaerobias 150 años después de su descubrimiento por Pasteur. Enferm Infecc Microbiol Clin. 2013. http:// dx.doi.org/10.1016/j.eimc.2013.03.012.

7. Brazier JS, Hall V, Yusuf E, Dueren Bl. Fusobacterium necrophorum infections in England and Wales 1990-2000. J Med Microbiol 2002;51: 269-272.

8. Riordan T, Wilson M. Lemierre's syndrome: more than a historical curiosa. Postgrad Med J 2004;80: 328-338.

9. Hagelskjaer Kristensen L, Prag J. Lemierre's syndrome and other disseminated Fusobacterium necrophorum infections in Denmark: a prospective epidemiological and clinical survey. Eur J Clin Microbiol Infect Dis 2008; 27: 779-789.

10. Valley TS, Sheshadri A, Hoopman TC. A young man with empyema. A report of isolated fusobacterial disease. Infect Dis Clin Pract 2011;19 (6): e31-e32.

11. Afra K, Laupland K, Leal J, Lloyd T, Gregson D. Incidence, risk factor, and outcomes of Fusobacterium species bacteremia. BMC Infect Dis. 2013 Jun 5;13(1): 264. 